Pacific Journal of Mathematics

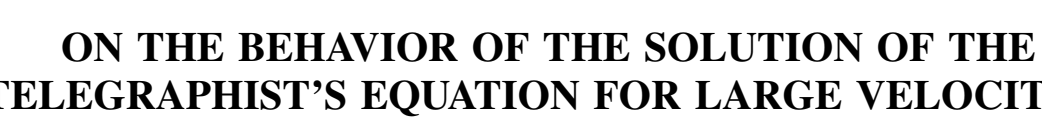




\section{ON THE BEHAVIOR OF THE SOLUTION OF THE TELEGRAPHIST'S EQUATION FOR LARGE VELOCITIES}

\section{LARRY E. BOBISUD}

Consider the solution $\varphi$ of the inhomogeneous telegraphist's equation with signal velocity $1 / \sqrt{ } \bar{\varepsilon}$, where $\varphi$ satisfies the initial conditions $\varphi(x, 0)=g(x), \varphi_{t}(x, 0)=h(x)$. Let $U$ be the solution of the parabolic equation that results from the telegraphist's equation when the velocity is set equal to $\infty(\varepsilon=0)$, and let $U$ satisfy the initial condition $U(x, 0)=g(x)$. Our main result is that, under suitable conditions on the coefficients and data,

$$
\int_{-\infty}^{\infty}[\varphi(x, t)-U(x, t)]^{2} d x=0(\sqrt{ } \bar{\varepsilon})
$$

uniformly in $0 \leqq t \leqq \bar{t}$ for any finite $\bar{t}$.

We shall investigate the behavior of the solution of the telegraphist's equation

$$
\frac{1}{c^{2}} a^{\prime} \varphi_{t t}+b^{\prime} \varphi_{t}-c^{\prime} \varphi_{x x}=f^{\prime}
$$

where $a^{\prime}>0, b^{\prime}>0, c^{\prime}>0$, as the velocity $c$ becomes large. For ease of writing, we will treat explicitly only the case of one space dimension, although the method employed will obviously extend to any number of space variables. Since we suppose that $c^{\prime}$ is never zero, we can write the telegraphist's equation in the form

$$
\varepsilon a(x, t) \varphi_{t t}+b(x, t) \varphi_{t}-\varphi_{x x}=f(x, t),
$$

where $\varepsilon=1 / c^{2}$ is a small parameter. We shall require that the solution $\varphi$ satisfy the initial conditions

$$
\begin{aligned}
\varphi(x, 0) & =g(x) \\
\varphi_{t}(x, 0) & =h(x)
\end{aligned}
$$

for each $\varepsilon>0$. Clearly $\varphi$ depends on $\varepsilon$; when it is desirable to make this dependence explicit we shall write either $\varphi_{\varepsilon}$ or $\varphi(x, t ; \varepsilon)$, and similarly for other quantities which may depend on $\varepsilon$.

If we set $\varepsilon=0$ in eq. (1) we get a parabolic equation

$$
b(x, t) U_{t}-U_{x x}=f(x, t)
$$

called the degenerate equation corresponding to eq. (1). Since this equation is of first order in $t$, we cannot hope to impose both initial 
conditions (2) on its solution; but the function $U$ can satisfy the single initial condition

$$
U(x, 0)=g(x) .
$$

If $a, b, f, g, h$ are sufficiently well behaved functions, then, as is well known, eqs. (1), (2) and (3), (4) will form correct problems having unique solutions $\varphi_{\varepsilon}$ and $U$, respectively. It seems reasonable to expect that $\varphi_{\varepsilon} \rightarrow U$ as $\varepsilon \rightarrow 0$, and we shall show that in terms of a certain norm to be introduced this does indeed happen wherever $U$ is defined (normally only for $t \geqq 0$ ). Moreover, as a step in this direction we shall show that, in a certain other norm, $\varphi_{t}(x, t ; \varepsilon) \rightarrow U_{t}(x, t)$ and $\varphi_{x}(x, t ; \varepsilon) \rightarrow U_{x}(x, t)$.

The degeneration of the solution of the pure Cauchy problem for the telegraphist's equation with constant coefficients has been studied by means of the Fourier transform [1], [5]. Also, the mixed problem for the equation

$$
\varepsilon u_{t t}+\beta(t) u_{t}-L u=F(x, t),
$$

where $L$ is an elliptic operator whose coefficients do not depend on $t$, has been studied, again using Fourier methods [4]. In this paper, however, we do not much restrict the coefficients, except that they must of course be positive and sufficiently smooth, and we deal directly with the degeneration by means of an energy-integral technique, rather than by actually constructing the solutions (which are well known to exist) by a Fourier method. However, our estimates are then in an $L^{2}$ norm instead of the sup norm.

In the papers referred to above it is shown that, in fact, $\phi \rightarrow U$ and $\varphi_{x} \rightarrow U_{x}$ pointwise uniformly for $t \in[0, \bar{t}]$, any $\bar{t}>0$, but that $\varphi_{t} \rightarrow U_{t}$ pointwise only for $t \in[0, \bar{t}]$ and uniformly only for $t \in[\delta, \bar{t}]$, any $\delta>0$. This behavior is of course reasonable because at $t=0$ $\varphi_{t}=h$, a condition that $U_{t}$ cannot in general satisfy. No previous studies of the degeneration of the solution of eq. (1) have included considerations for $t<0$; the technique-reduction to a symmetric linear system-which we shall employ holds also for $t<0$ provided the solution $U$ of the parabolic problem (3), (4) exists for negative $t$. (This can happen, see [3], [1].) We shall not explicitly be concerned with the possibility of negative $t$ in the following, but the argument goes through there if $U$ exists and satisfies the conditions to be imposed.

Concerning the problem (3), (4) we shall assume only that a solution $U$ exists and is smooth enough that $U_{t t}(x, t)$ is continuous and square integrable over the domain $\mathscr{R}=\{(x, t): 0 \leqq t \leqq \bar{t}\}$ for any $\bar{t}>0$. This will, for instance, be the case if $b, f$, and $g$ are suf- 
ficiently smooth and, for some constant $\alpha>0, \alpha b-(1 / 2) b_{t}>0$ holds for all $(x, t) \in \mathscr{R}$; this can be seen by writting eq. (3) as a symmetric positive system in $e^{-\alpha t} U$ and $e^{-\alpha t} U_{x}$ for a suitable $\alpha$ (cf. [2]).

We set $\psi=\varphi-U$, where $\varphi$ satisfies eqs. (1), (2) and $U$ satisfies (3), (4), and proceed to determine a problem which $\psi$ satisfies. This is easily seen to be

$$
\begin{aligned}
\varepsilon a \psi_{t t}+b \psi_{t}-\psi_{x x} & =-\varepsilon a U_{t t} \\
\psi(x, 0) & =0 \\
\psi_{t}(x, 0) & =h(x)-U_{t}(x, 0),
\end{aligned}
$$

the inhomogeneous telegraphist's equation with inhomogeneous data of a special form. It is this problem for $\psi$ that we shall consider in detail.

We introduce the following inner products and corresponding norms, in terms of which our results will be formulated. For vectors $u=\left(\begin{array}{l}u_{1} \\ u_{2}\end{array}\right)$ and $v=\left(\begin{array}{l}v_{1} \\ v_{2}\end{array}\right)$ we set $(u, v)=u^{\prime} v=u_{1} v_{1}+u_{2} v_{2}$, where $u^{\prime}$ is the transpose of $u$; for functions (i.e., 1-vectors), we set $(u, v)=u v$. Which of these inner products is meant will always be clear from the context. If for fixed $t, u$ and $v$ are square integrable in $x$, we set

$$
(u, v)_{t}=\int_{-\infty}^{\infty}(u(x, t), v(x, t)) d x ;
$$

if moreover $u$ and $v$ are integrable over the domain

$$
\mathscr{R}=\{(x, t):-\infty<x<\infty, 0 \leqq t \leqq \bar{t}\},
$$

we set

$$
(u, v)_{\mathscr{R}}=\int_{0}^{\bar{t}}(u, v)_{t} d t=\iint_{\mathscr{R}}(u(x, t), v(x, t)) d x d t .
$$

As customary, we set $(u, u)_{t}=\|u\|_{t}^{2},(u, u)_{\mathscr{R}}=\|u\|_{\mathscr{R}}^{2}$.

Our main result is then

THEOREM. Let $a, b, f, g, h$ be sufficiently smooth and $f, g, h$ in $L^{2}(\mathscr{R})$. In addition, let $b$ and a satisfy the condition that for some $\varepsilon_{0}>0$ and some $\delta>0$ the inequality

$$
2 b-\varepsilon a_{t} \geqq 2 \delta
$$

holds for all $(x, t) \in \mathscr{R}$ and all $\varepsilon \in\left(0, \varepsilon_{0}\right]$. The smoothness conditions on the coefficients and data are such that a $C^{2}(\mathscr{R})$ and $L^{2}(\mathscr{R})$ solution $\varphi$ of (1), (2) exists with $\varphi_{t}$ and $\varphi_{x}$ also in $L^{2}(\mathscr{R})$ and that a $C^{2}(\mathscr{R})$ solution $U$ of (3), (4) exists such that $U_{t t}$ satisfies the same 
conditions as were imposed on $f$ for a suitable solution of (1), (2) to exist. These conditions being met, we have

$$
\left\|\psi_{\varepsilon}\right\|_{t}=\left\|\varphi_{\varepsilon}-U\right\|_{t}=0(\sqrt{\varepsilon})
$$

uniformly for $0 \leqq t \leqq \bar{t}$, any $\bar{t}$ finite.

As noted above, the proof is easily modified so that the theorem holds for negative $t$, provided a sufficiently will behaved solution of the degenerate problem exists for $t<0$.

The smoothness conditions which the coefficients must satisfy may be found, for instance, by reducing the problem to a symmetric linear system of first-order equations, as in [2].

As a step in establishing this theorem we shall first prove the following lemma.

Lemma. Under the conditions of the Theorem,

$$
\begin{aligned}
& \left\|\psi_{t}\right\|_{\mathscr{R}}=0(\sqrt{\bar{\varepsilon}}), \\
& \left\|\psi_{x}\right\|_{\mathscr{R}}=0(\sqrt{\varepsilon}) .
\end{aligned}
$$

We begin by writing eq. (5) as a system in the two variables $u_{1}=e^{-\lambda t} \psi_{t}$ and $u_{2}=e^{-\lambda t} \psi_{x}$ for a $\lambda$ to be determined. In terms of $u=\left(\begin{array}{l}u_{1} \\ u_{2}\end{array}\right)$ this system is

$$
L u=\left(\begin{array}{cc}
\varepsilon a & 0 \\
0 & 1
\end{array}\right) u_{t}+\left(\begin{array}{rr}
0 & -1 \\
-1 & 0
\end{array}\right) u_{x}+\left(\begin{array}{cc}
\varepsilon a \lambda+b & 0 \\
0 & \lambda
\end{array}\right) u=\left(\begin{array}{c}
-\varepsilon a e^{-\lambda t} U_{t t} \\
0
\end{array}\right) ;
$$

the initial data for $u$ are clearly

$$
u(x, 0 ; \varepsilon)=\left(\begin{array}{c}
h(x)-U_{t}(x, 0) \\
0
\end{array}\right) .
$$

Defining the matrix $k$ as

$$
k=\left(\begin{array}{cc}
\varepsilon a \lambda+b & 0 \\
0 & \lambda
\end{array}\right)-\frac{1}{2}\left(\begin{array}{cc}
\varepsilon a_{t} & 0 \\
0 & 0
\end{array}\right),
$$

we wish to determine $\lambda$ so that $1 / 2\left(k+k^{\prime}\right)$, where $k^{\prime}$ denotes the transpose of $k$, is positive definite. But for $\lambda=\delta$, where $\delta$ is the constant of the theorem, we have

$$
\frac{1}{2} u^{\prime}\left(k+k^{\prime}\right) u=u^{\prime} k u=\left[\varepsilon a \lambda+\frac{1}{2}\left(2 b-\varepsilon \alpha_{t}\right)\right] u_{1}^{2}+\lambda u_{2}^{2} \geqq \lambda u^{\prime} u ;
$$

whence, moreover, 


$$
(u, k u)_{\mathscr{R}} \geqq \lambda\|u\|_{\mathscr{R}}^{2},
$$

an inequality which will be needed later.

Following Friedrichs [2], and using the "divergence theorem" and the fact that $L u$ can be written as

$$
\begin{aligned}
L u=\frac{1}{2}\left(\begin{array}{cc}
\varepsilon a & 0 \\
0 & 1
\end{array}\right) u_{t} & +\left[\frac{1}{2}\left(\begin{array}{cc}
\varepsilon a & 0 \\
0 & 1
\end{array}\right) u\right]_{t} \\
& +\frac{1}{2}\left(\begin{array}{rr}
0 & -1 \\
-1 & 0
\end{array}\right) u_{x}+\left[\frac{1}{2}\left(\begin{array}{rr}
0 & -1 \\
-1 & 0
\end{array}\right) u\right]_{x}+k u,
\end{aligned}
$$

we calculate $(u, L u)_{\mathscr{R}}$ for any two-vector $u \in C^{1}(\mathscr{R})$ which, together with its first derivatives, is in $L^{2}(\mathscr{R})$ :

$$
\begin{aligned}
(u, L u)_{\mathscr{R}}= & \frac{1}{2} \iint_{\mathscr{R}}\left[\left(u,\left(\begin{array}{cc}
\varepsilon a & 0 \\
0 & 1
\end{array}\right) u_{t}\right)+\left(u,\left\{\left(\begin{array}{cc}
\varepsilon a \\
0 & 1
\end{array}\right) u\right\}_{t}\right)\right. \\
& \left.+\left(u,\left(\begin{array}{rr}
0 & -1 \\
-1 & 0
\end{array}\right) u_{x}\right)+\left(u,\left\{\left(\begin{array}{rr}
0 & -1 \\
-1 & 0
\end{array}\right) u\right\}\right)\right] d x d t+(u, k u)_{\mathscr{R}} \\
= & \frac{1}{2} \iint_{\mathscr{R}}\left[\left(u,\left(\begin{array}{cc}
\varepsilon a & 0 \\
0 & 1
\end{array}\right) u\right)_{t}+\left(u,\left(\begin{array}{rr}
0 & -1 \\
-1 & 0
\end{array}\right) u\right)_{x}\right] d x d t+(u, k u)_{\mathscr{R}} \\
= & -\left.\frac{1}{2} \int_{-\infty}^{\infty}\left(u,\left(\begin{array}{cc}
\varepsilon a & 0 \\
0 & 1
\end{array}\right) u\right)\right|_{t=0} d x \\
& +\left.\frac{1}{2} \int_{-\infty}^{\infty}\left(u,\left(\begin{array}{cc}
\varepsilon a & 0 \\
0 & 1
\end{array}\right) u\right)\right|_{t=\bar{t}} d x+(u, k u)_{\mathscr{R}} .
\end{aligned}
$$

Thus we have, since $\left(\begin{array}{cc}\varepsilon a & 0 \\ 0 & 1\end{array}\right)$ is clearly positive definite for each $\varepsilon>0$,

$$
(u, L u)_{\mathscr{R}}+\frac{1}{2} \int_{-\infty}^{\infty}\left(u(x, 0),\left(\begin{array}{cc}
\varepsilon a(x, 0) & 0 \\
0 & 1
\end{array}\right) u(x, 0)\right) d x \geqq(u, k u)_{\mathscr{R}}
$$

for any continuously differentiable $u$ which, together with its first partial derivatives, is in $L^{2}(\mathscr{R})$. By choice of $\lambda$ we have $(u, k u)_{\mathscr{R}} \geqq$ $\lambda\|u\|_{\mathscr{R}}^{2}$, so we get

$$
\|u\|_{\mathscr{R}}\|L u\|_{\mathscr{R}}+\frac{1}{2} \int_{-\infty}^{\infty}\left(u(x, 0),\left(\begin{array}{cc}
\varepsilon a(x, 0) & 0 \\
0 & 1
\end{array}\right) u(x, 0)\right) d x \geqq \lambda\|u\|_{\mathscr{R}}^{2} .
$$

It is this energy inequality which yields the lemma. For we can write the solution $u$ of problem (7), (8) as $u=v+w$, where $v$ satisfies the homogeneous equation with inhomogeneous data and $w$ satisfies the inhomogeneous equation but homogeneous data. For $w$ inequality (9) yields

$$
\|L w\|_{\mathscr{R}}=\varepsilon\left\|e^{-\lambda t} a U_{t t}\right\|_{\mathscr{R}} \geqq \lambda\|w\|_{\mathscr{R}},
$$


whence also

$$
\varepsilon\left\|a U_{t t}\right\| \geqq \lambda\|w\|_{\mathscr{R}} ;
$$

from this it is clear that

$$
\|w\|_{\mathscr{B}}=0(\varepsilon) \text {, }
$$

which at once yields the weaker statement

$$
\|w\|_{\mathscr{R}}=(\sqrt{\varepsilon}) .
$$

Similarly for $v$ we have

$$
\frac{\varepsilon}{2} \int_{-\infty}^{\infty} a(x, 0)\left(h(x)-U_{t}(x, 0)\right)^{2} d x \geqq \lambda\|v\|_{\mathscr{R}}^{2},
$$

whence

$$
\|v\|_{\mathscr{B}}=0(\sqrt{\varepsilon}) \text {. }
$$

Thus $\|u\|_{\mathscr{R}}=0(\sqrt{\varepsilon})$. But $u=\left(e^{-\lambda t} \psi_{t}, e^{-\lambda t} \psi_{x}\right)^{\prime}=e^{-\lambda t} \psi_{0}$, say, and it follows that $\left\|\psi_{0}\right\|_{\mathscr{R}}=0(\sqrt{\varepsilon})$. Since

$$
\left\|\psi_{0}\right\|_{\mathscr{R}}^{2}=\iint_{\mathscr{R}} \psi_{t}^{2}+\psi_{x}^{2}=\left\|\psi_{t}\right\|_{\mathscr{T}}^{2}+\left\|\psi_{x}\right\|_{\mathscr{R}}^{2}
$$

we conclude that

$$
\left\|\psi_{t}\right\|_{\mathscr{A}}=0(\sqrt{\bar{\varepsilon}}),\left\|\psi_{x}\right\|_{\mathscr{B}}=0(\sqrt{\bar{\varepsilon}})
$$

completing the proof of the lemma.

The theorem is an easy consequence of the lemma and the following simple estimate:

$$
\left[\int_{0}^{t} f(\tau) d \tau\right]^{2} \leqq t \int_{0}^{t} f^{2}(\tau) d \tau
$$

For we have

$$
\begin{aligned}
\|\psi\|_{t_{0}}^{2} & =\left\|\int_{0}^{t_{0}} \psi_{t} d t\right\|_{t_{0}}^{2}=\int_{-\infty}^{\infty}\left\{\int_{0}^{t_{0}} \psi_{t} d t\right\}^{2} d x \leqq t_{0} \int_{-\infty}^{\infty} \int_{0}^{t_{0}} \psi_{t}^{2} d t d x \\
& \leqq \bar{t} \int_{-\infty}^{\infty} \int_{0}^{\bar{t}} \psi_{t}^{2} d t d x=\bar{t}\left\|\psi_{t}\right\|_{\mathscr{T}}^{2}=[0(\sqrt{\bar{\varepsilon}})]^{2}
\end{aligned}
$$

for any $t_{0} \in[0, \bar{t}]$. Hence the theorem is established.

REMARK. The lemma and theorem proved above are equally true for the mixed boundary-initial value problem with homogeneous boundary data. For our entire proof has depended only upon the existence of the energy estimate eq. (9), which in turn depends only 
on writing the problem (5), (6) as a symmetric linear system with admissible boundary-initial conditions. Since that can be done for the mixed problem as well as for the pure Cauchy problem for the case at hand [2], the theorem is equally true in both cases.

It should also be observed that the considerations used here can doubtless be used in studying the degeneration of the solutions of other problems which can be written as symmetric linear systems with admissible boundary-initial data.

I wish to thank Professor Reuben Hersh for several stimulating conversations.

\section{REFERENCES}

1. L. Bobisud, Degeneration of the solutions of certain well posed systems of partial differential equations depending on a small parameter, J. of Math. Anal. and Appl. 16 (1967), 419-454.

2. K. O. Friedrichs, Symmetric positive linear differential equations, Comm. Pure Appl. Math. 11 (1958), 333-418.

3. J. W. Miranker, A well posed problem for the backwards heat equation, Proc. Amer. Math. Soc. 12 (1961), 243-247.

4. M. Zlámal, The mixed boundary value problem for hyperbolic equations with a small parameter (Russian), Czech. Math. J. 10 (1960), 83-122.

5. - Sur l'équation des télégraphistes avec un petit paramètre, Atti Accad. Naz. Lincei Rend. Cl. Sci. Fis. Mat. Nat. (8) 27 (1959), 324-332.

Received May 5, 1966. Research supported by NASA NsG(T)-62.

UNIVERSITY OF NEW MEXICO 



\section{PACIFIC JOURNAL OF MATHEMATICS}

\section{EDITORS}

\section{H. SAMELSON}

Stanford University

Stanford, California

J. P. JANS

University of Washington

Seattle, Washington 98105

\section{J. DugundJI}

University of Southern California Los Angeles, California 90007

RICHARD ARENS

University of California

Los Angeles, California 90024

\section{ASSOCIATE EDITORS}

E. F. BECKENBACH
B. H. NeUmanN

\section{SUPPORTING INSTITUTIONS}

UNIVERSITY OF BRITISH COLUMBIA CALIFORNIA INSTITUTE OF TECHNOLOGY

UNIVERSITY OF CALIFORNIA

MONTANA STATE UNIVERSITY

UNIVERSITY OF NEVADA

NEW MEXICO STATE UNIVERSITY

OREGON STATE UNIVERSITY

UNIVERSITY OF OREGON

OSAKA UNIVERSITY

UNIVERSITY OF SOUTHERN CALIFORNIA

\author{
STANFORD UNIVERSITY \\ UNIVERSITY OF TOKYO \\ UNIVERSITY OF UTAH \\ WASHINGTON STATE UNIVERSITY \\ UNIVERSITY OF WASHINGTON \\ AMERICAN MATHEMATICAL SOCIETY \\ CHEVRON RESEARCH CORPORATION \\ TRW SYSTEMS \\ NAVAL ORDNANCE TEST STATION
}

Mathematical papers intended for publication in the Pacific Journal of Mathematics should be typewritten (double spaced). The first paragraph or two must be capable of being used separately as a synopsis of the entire paper. It should not contain references to the bibliography. Manuscripts may be sent to any one of the four editors. All other communications to the editors should be addressed to the managing editor, Richard Arens at the University of California, Los Angeles, California 90024.

50 reprints per author of each article are furnished free of charge; additional copies may be obtained at cost in multiples of 50 .

The Pacific Journal of Mathematics is published monthly. Effective with Volume 16 the price per volume ( 3 numbers) is $\$ 8.00$; single issues, $\$ 3.00$. Special price for current issues to individual faculty members of supporting institutions and to individual members of the American Mathematical Society: $\$ 4.00$ per volume; single issues $\$ 1.50$. Back numbers are available.

Subscriptions, orders for back numbers, and changes of address should be sent to Pacific Journal of Mathematics, 103 Highland Boulevard, Berkeley 8, California.

Printed at Kokusai Bunken Insatsusha (International Academic Printing Co., Ltd.), 7-17, Fujimi 2-chome, Chiyoda-ku, Tokyo, Japan.

\section{PUBLISHED BY PACIFIC JOURNAL OF MATHEMATICS, A NON-PROFIT CORPORATION}

The Supporting Institutions listed above contribute to the cost of publication of this Journal, but they are not owners or publishers and have no responsibility for its content or policies. 


\section{Pacific Journal of Mathematics}

\section{Vol. 22, No. $2 \quad$ February, 1967}

Paul Frank Baum, Local isomorphism of compact connected Lie groups ....

Lowell Wayne Beineke, Frank Harary and Michael David Plummer, On the

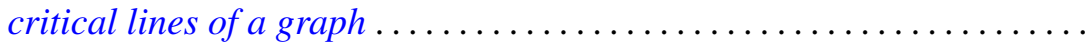

Larry Eugene Bobisud, On the behavior of the solution of the telegraphist's equation for large velocities .......................... 213

Richard Thomas Bumby, Irreducible integers in Galois extensions . . . . . . 221

Chong-Yun Chao, A nonimbedding theorem of nilpotent Lie algebras ..... 231

Peter Crawley, Abelian p-groups determined by their Ulm sequences ...... 235

Bernard Russel Gelbaum, Tensor products of group algebras ........... 241

Newton Seymour Hawley, Weierstrass points of plane domains .......... 251

Paul Daniel Hill, On quasi-isomorphic invariants of primary groups . . . . . 257

Melvyn Klein, Estimates for the transfinite diameter with applications to confomral mapping ................................ 267

Frederick M. Lister, Simplifying intersections of disks in Bing's side approximation theorem ............................. 281

Charles Wisson McArthur, On a theorem of Orlicz and Pettis ........... 297

Harry Wright McLaughlin and Frederic Thomas Metcalf, An inequality for

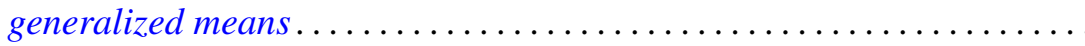

Daniel Russell McMillan, Jr., Some topological properties of piercing

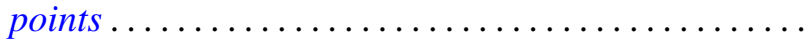

Peter Don Morris and Daniel Eliot Wulbert, Functional representation of topological algebras .

Roger Wolcott Richardson, Jr., On the rigidity of semi-direct products of Lie algebras..................................

Jack Segal and Edward Sandusky Thomas, Jr., Isomorphic

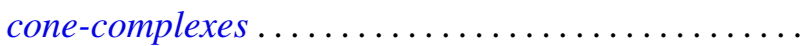

Richard R. Tucker, The $\delta^{2}$-process and related topics.... 